九州大学学術情報リポジトリ

Kyushu University Institutional Repository

\title{
Ultrastructure of the Fungus Causing Rust on Broadbean in Bangladesh
}

Hossain, Ismail

Department of Plant Pathology, Institute of Postgraduate Studies in Agriculture (IPSA)

Tsuno, Kazunori

Laboratory of Plant Pathology, Faculty of Agriculture, Kyushu University

https://doi.org/10.5109/23889

出版情報: 九州大学大学院農学研究院紀要. 34 (1/2)，pp.69-75，1989-11. Kyushu University バージョン：

権利関係 : 


\title{
U Itrastructure of the $F$ ungus Causing $R$ ust on Broadbean in Bangladesh
}

\author{
Ismail Hossain Mian and Kazunori Tsuno* \\ Department of Plant Pathology, Institute of Postgraduate \\ Studies in Agriculture (IPSA), Salna, Gazipur, Bangladesh \\ *Laboratory of Plant Pathology, Faculty of Agriculture, \\ Kyushu University, Fukuoka 812, Japan
}

(Received May 15, 1989)

\begin{abstract}
The characteristic features of the fungus causing rust on broadbean (Vicia faba) were recorded and the fungus was identifies as Uromyces vicia-fabae. Ultrastructural observation on different types of spores and infection structures of the fungus were made using scanning electron microscope. Aecia were observed on the abaxial leaf surface having smooth walled aeciospores in small groups. Uredia are amphigenous, urediospores are broadly ellipsoid to globoid, pedicilate and uniformly echinulate, spines pointed and germ pores 5-7, scattered on the wall of urediospores. Telia were observed on both leaf surfaces, teliospores are obovoid with smooth wall and short pedicel. In some cases, urediospores and teliospores were found to present in the same pustule. Germinating urediospores were found on the leaf. When they germinated close to stomata, their germlings formed appressoria over them and short infection pegs developed from the appressoria put forth into the stomatal aperture. Well branched intercellular mycelia were also observed in the cells of infected leaves. Cylindrical and slightly curved substomatal vesicles and bilobed haustoria were found in the cross sections of leaves.
\end{abstract}

\section{INTRODUCTION}

Rust fungi have to undergo morphological changes before they can infect a host plant. The initiation of their penetration into the hosts involves a considerable complicated process. Urediospores germinate on leaf surface, the germlings go through a series of morphological events forming sequentially appresoria, infection peg, substomatal vesicles, infection hyphae and haustoria mother cells. It was demonstrated using scanning electron micrographs of artificially induced infection structures that every rust species has a characteristic, different, external morphology which is apparently identical to that seen during host infection (Paliwal and Kim, 1974 ; Wynn, 1976 ; Harder, 1984 ; Staples and Mack, 1984). Uromyces vicia-fabae (Pers.) Schroet is a circumglobal fungus causing rust on various species of plants (Cummins and Stevenson, 1964 ; Kapoori and Sinha, 1966 ; Talukder, 1974 ; Cummins, 1978 ; Hossain and Miah, 1988). Broadbean is a common pulse in Bangladesh. It was also found to be attacked by rust but its causal fungus yet to be reported. Detailed features of various structures of the fungus developed on broadbean leaves have not yet been studied in the country.

The present piece of work was undertaken to identify the causal fungus of the disease and to study the characteristic features of different types of spores and infection structures of the pathogen, developed on broadbean leaves under natural 
conditions of Bangladesh, using scanning electron microscope (SEM).

\section{MATERIALS AND METHODS}

Symptoms of the disease were recorded observing naturally infected plants of broadbean grown at the experimental farm of Institute of Postgraduate Studies in Agriculture (IPSA), Salna, Gazipur, Bangladesh during winter 1987-88. Infected leaves of various ages were collected from the field for SEM observation. Small pieces (3 $\mathrm{mm} \times 3 \mathrm{~mm}$ ) of infected leaves were prefixed in $2.5 \%$ glutaraldehyde in $0.1 \mathrm{M}$ phosphate buffer ( $\mathrm{pH} \mathrm{7.4)} \mathrm{for} 4 \mathrm{hr}$ and postfixed in $2 \%$ osmium tetroxide in the same buffer for ' $2 \mathrm{hr}$ at room temperature and dehydrated with a series of five graded ethanol viz. 50, 70, 90, 99.5 and $100 \%$ ethanol for 5, 10, 20, 40 and $60 \mathrm{~min}$, respectively. The dehydrated specimens were dried in a vacuum desicator attached to a running water aspirator for $3 \mathrm{hr}$. The specimens were mounted on SEM stub with double side adhesive tape, coated with gold (ca. $230 \AA$ ) with a JFC-1100 Ion Sputter and observed under a JEM T-220 SEM at $10 \mathrm{KV}$ accelerating voltage. The important features of different types of spores and infection structures developed by the fungus were recorded. The fungus was identified following the descriptions of Cummins (1978).

\section{RESULTS AND DISCUSSION}

The disease was manifested by its characteristic symptoms. Pustules of rust were observed on the leaves and stems after blossoming. Reddish brown pustules of uredia were found on both surfaces of leaf, whereas aecia were observed only on the lower surface in small groups. The teliospores were also observed on both surfaces of leaf and they were mostly obovoid with smooth wall. The causal fungus was identified as Uromyces vicia-fabae.

Young and developed uredia were observed underneath the leaf cuticle. Growing urediospores push the cuticle upward (Fig. 1A). At maturity the uredia were observed to break through the leaf cuticle and densely populated urediospores appear in the pustules which are surrounded by fragments of ruptured host cuticle (Fig. 1B and C). Matured urediospores are broadly elipsoid, uniformly echinulate with 5-7 germ pores on the wall (Fig. 1D). Pedicel of urediospores is short and looks like the jointed femur and tibia of an insect (Fig. 2A). The spines are conical, pear-shaped with pointed and slightly curved tip. They are uniformly distributed on the spore wall. The spines reside in small polygonal depression with raised annuli (Fig. 2B). Uredia and urediospores are comparatively larger than aecia and aeciospores respectively (Fig. 2C). In some cases, urediopsores and teliospores were found in the same pustules (Fig. 2D).

Germinating urediopsores were observed over stomata and also away from them. The germlings formed over the protruding stomatal lips gave rise to appressoria (Fig. 3A). The appressoria developed over stomata were found to form short infection pegs which put forth into the stomatal aperture (Fig. 3B). The process of appressorium and infection peg development indicates the ability of the fungus to enter the host through the stomatal aperture, as recorded in other rust fungi (Wynn, 1976 ; Harder, 1984). When urediospores were found to germinate away from stomatal aperture or the 

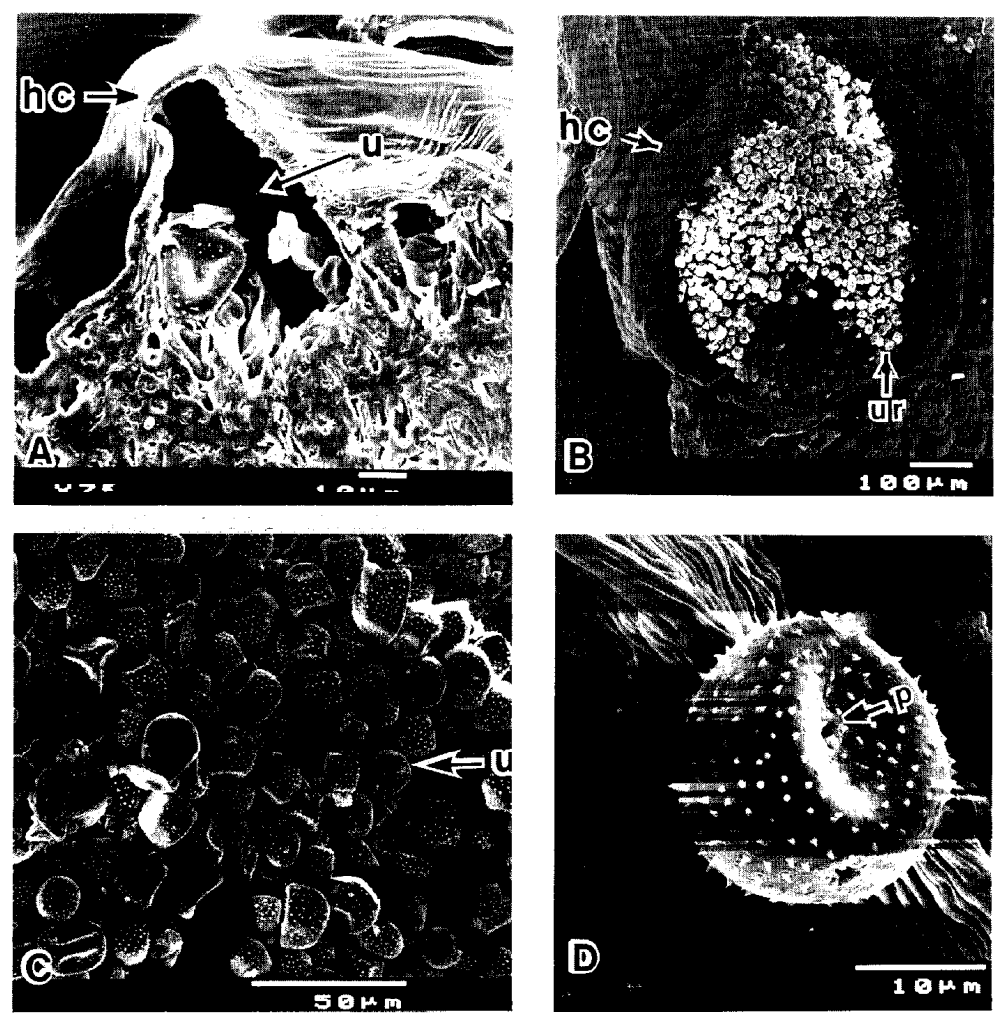

Fig. 1. Scanning electron micrographs of different structures of Vromyces vicia-fabae on broadbean.

(A) Developing urediospores (u) pushing the leaf cuticle (hc).

(B) Uredial pustule breaks through the host cuticle :(ur) Urediospores, (hc) fragments of ruptured host cuticle.

(C) Mass of urediospores (u).

(D) Urediospores with germ pores (p).

sporelings failed to find an open stoma the appresorium became extremely larger, flattened and bulky (Fig. 3C). Wynn (1976) also found similar types of appressoria when the urediospores of $U$.phaseolitypica germinated over closed stomata and on intact artificial membranes. It was also observed that urediospores of U.vicia-fabae can germinate on dead and dried leaves of broadbean under natural conditions but appressoria are formed only when the leaf surface was wavy with large ridges (Fig. 3C). The germling developed from a urediospore germinated on older leaf naving smooth surface and no stomatal lip was found to be elongated, cylindrical and comparatively narrow, and it did not form appressorium (Fig. 4D). The present findings indicate that U.vicia-fabae needs protruding stomatal lips or wavy leaf surface with 

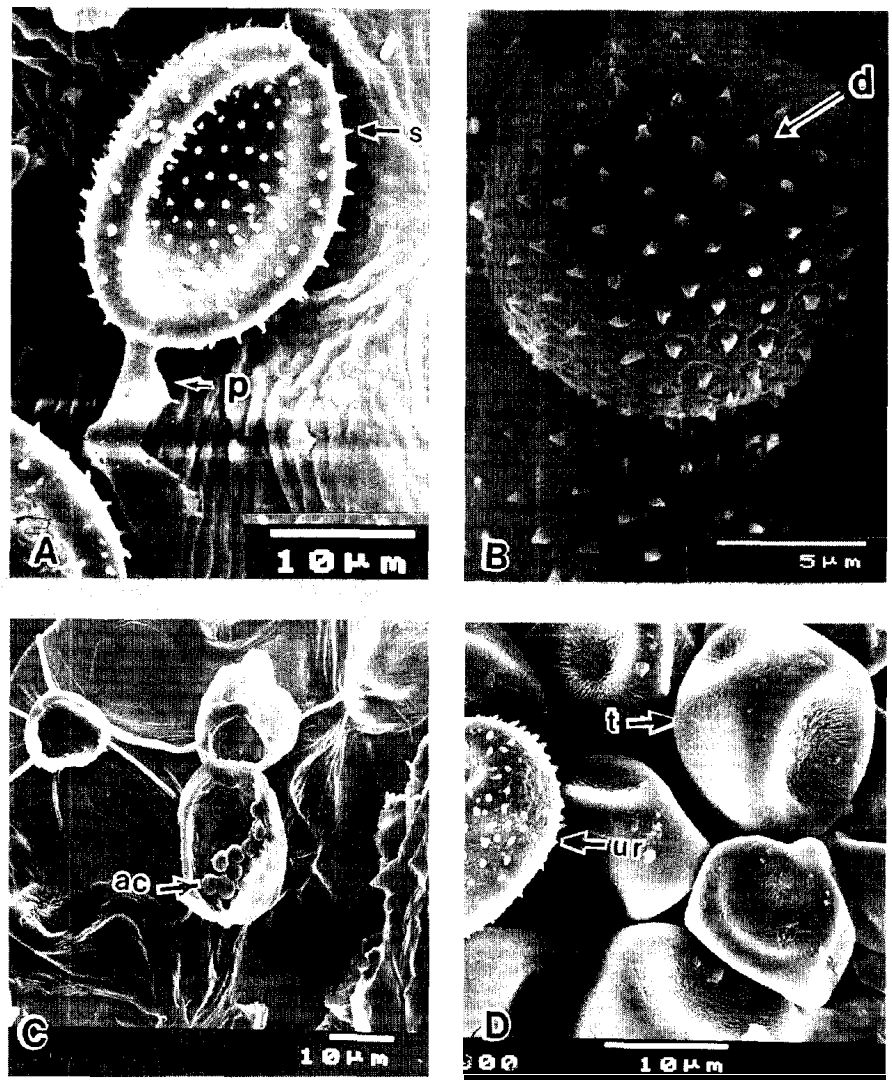

Fig. 2. Scanning electron micrographs of urediospores, aeciospores and teliospores of Uromyces vicia-fabae.

(A) Urediospores with spines (s) and pedicel (p).

(B) Spines on the urediospore reside in small polygonal depression (d).

(C) Aecium with aeciospores (ac).

(D) Teliospores (t) and urediospores (ur) in the same pustule.

large ridges to form appressoria, like U.phaseolitypica. Using scanning electron microscopy of artificial membranes, it was shown that $U$. phaseolitypica forms appressoria only when their urediosporelings grow over the relatively large ridges of craters and scratches. The investigator mentioned that similar natural stimuli might be the protruding stomata1 lips (Wynn, 1976).

Cylindrical and slightly curved vesicles (Fig. 4A) and bilobed haustoria (Fig. 4B) were found in the epidermal cells of leaves. Well branched intercelullar mycelia were observed in the cells of infected leaves (Fig. 4C). In some cases, tips of growing hyphae were found to push out through the stomata of the lower surface of leaves (Fig. 4D). 

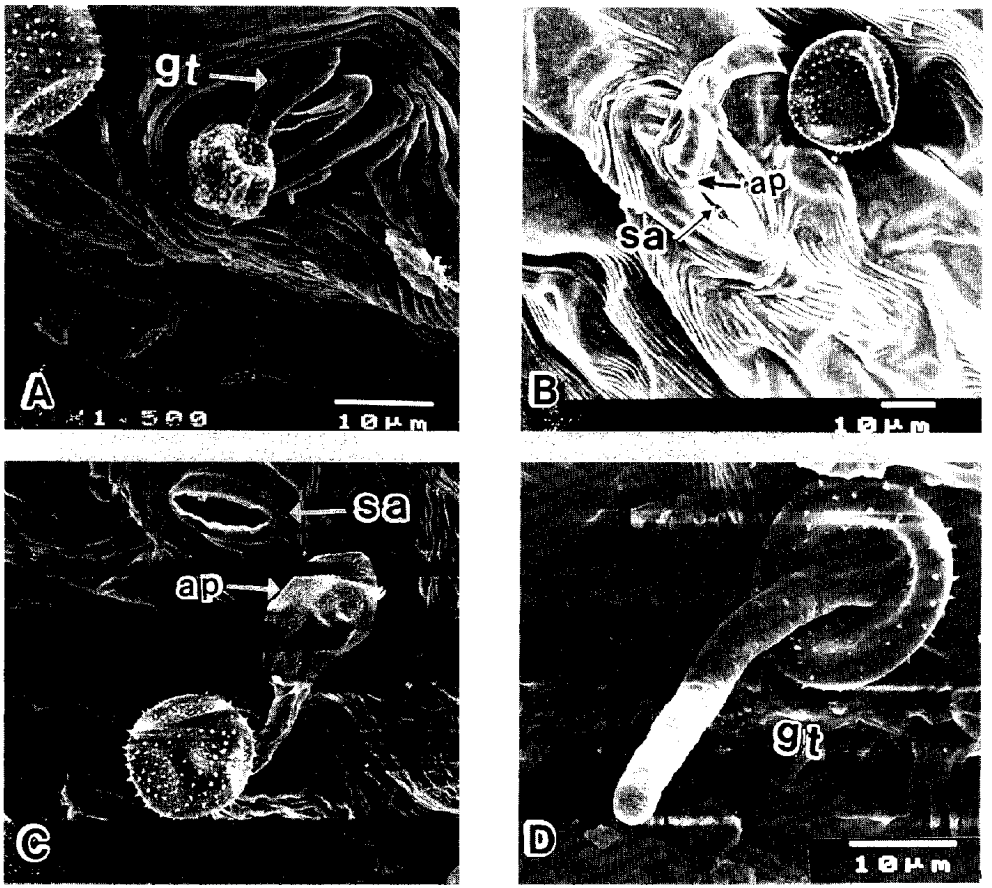

Fig. 3. Scanning electron micrographs of germinating urediospores of Uromyces vicia-fabae on broadbean.

(A) A urediospore germinating over a stomata1 lip : (gt) developing germ tube and its tip passed away the opening.

(B) An appressorium developed over a stomata1 lip and an infection peg formed by it entered into stomata : (ap) appressorium, (sa) stomatal aperture.

(C) Large and flattened appressorium formed by a germ tube which failed to find a stomata1 aperture : (ap) appressorium, (sa) stomata1 aperture.

(D) A germinated urediospore on a older leaf having smooth surface and no stomata. The germ tube fails to form appressorium : (gt) germ tube.

The characteristic features of various structures and their activities recorded in the present study were in accordance with the findings of other investigators who studied with other rust fungi (Dickson, 1970 ; Paliwal and Kim, 1974, Wynn, 1976). Findings of the present study also indicate that the urediosporeling of U.vicia-fabae goes through a series of complicated morphological events on broadbaen under natural conditions of Bangladesh forming appressoria, infection pegs, substomatal vesicles and haustoria. 

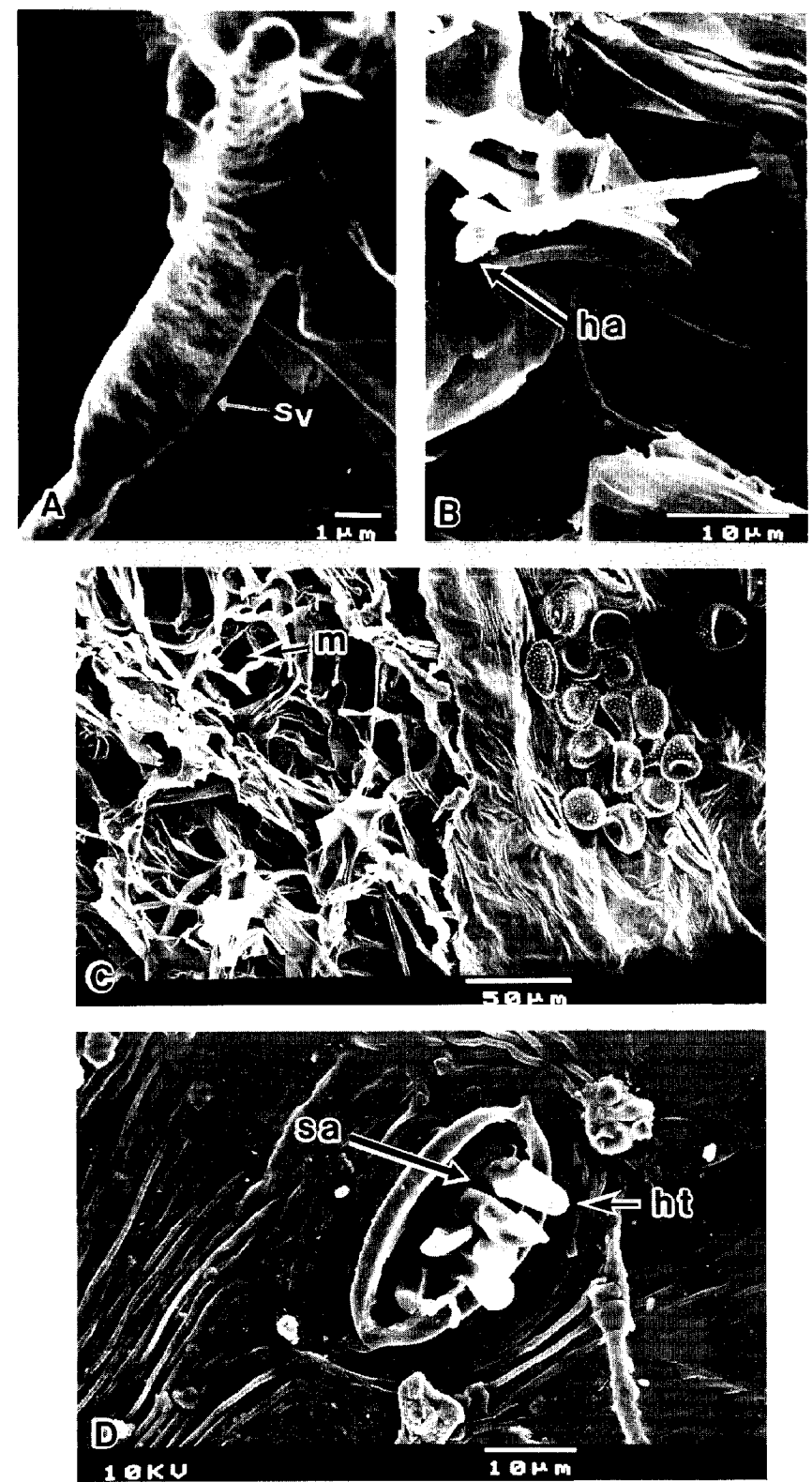

Fig. 4. Scanning electron micrographs of infection structures of Uromyces vicia-fabae on broadbean.

(A) A cylindrical and slightly curved substomatal vesicle (sv).

(B) Bilobed haustorium (ha).

(C) Intercellular mycelia in leaf tissues : (m) mycelia.

(D) Intercellular mycelium growing out through the stomatal aperture: (ht) tip of growing hyphae, (sa) stomatal aperture. 


\section{ACKNOWLEDGEMENTS}

The authors wish to thank Japan International Cooperation Agency (JICA) for providing the Institute of Postgraduate Studies in Agriculture (IPSA), Salna, Gazipur, Bangladesh, where this study was undertaken, with equipments which were used to make this study a success. They would also like to thank Dr. Nobuaki Matsuyama, Associate Professor, Laboratory of Plant Pathology, Faculty of Agriculture, Kyushu University, Fukuoka, Japan for his valuable comments on the manuscript.

\section{REFERENCES}

Cummins, G. B. 1978 R ust fungi on legumes and composites in North America. Univ. Arizona Press, Tucoson, Arizona. pp. 215

Cummins, G. B. and J. A. Stevenson 1964 A check list of North American rust fungi (Uredinales). Plant Dis. Rept. Supl. 240 : 109-193

Dickson, S. 1970 Studies in the physiology of obligate parasitism. Phytopathol.Z.69: 115-124

Harder, D. E. 1984 Developmental structure of hyphae and spores. In “The cereal rusts” Ed. by W. R. Bushnell and P. A. Roelfs. Academic Press Inc. New York. pp. 333-373

Hossain, M. M. and M. A. Jabber Miah 1988 Two new hosts of Uromyces vicia-fabae from Bangladesh. Bangladesh J. Bot. 17 (1) : 99-101

Kapoori, S. and S. Sinha 1966. Studies on the host range of Uromyces faba (Pers.) de Bary. Indian Phytopath. 10 (2) : 229-230

Paliwal, Y. C. and W. K. Kim 1974 Scanning electron micrography of differentiating and not differentiating urediosporelings of wheat stem rust fungus (Puccinia graministritici) on an artificial substance. Tissue and Cell. 6: 391-397

Staples, R. C. and V. Mack 1984 Germination of urediospores and differentiation of infection structures. In “The cereal rusts.” Ed. by W. R. Bushnell and A. P Roelfs. Academic Press Inc. New York. pp. 333-373

Talukdar, M. J. 1985 Plant diseases in Bangladesh. Bangladesh J.Agric. Res. 1: 61-86

Wynn, W. K. 1976 Appressorium formation over stomata by the bean rust fungus: Response to a surface contact stimulus.

Phytopathology. 66 : 136-146' 